\title{
Applications of picosecond lasers beyond tattoos: pigment reduction and tissue remodeling
}

\author{
Emily Forbat $^{1} \cdot$ Faisal R. Ali $^{1} \cdot$ Firas Al-Niaimi $^{1}$
}

Received: 16 November 2016/Accepted: 30 January 2017 / Published online: 9 February 2017

(C) Springer-Verlag London 2017

We read the recent review regarding the use of picosecond lasers for tattoo removal with interest. Whilst the evidence underlying tattoo treatment is equivocal, there are promising results for other indications [1] for which picosecond laser use may be better tolerated or more effective.

The ultra-short pulse duration of the picosecond laser imparts a predominantly photo-acoustic effect on the tissue and has fewer side effects (such as dyspigmentation, scarring) and shorter postprocedural downtime. As such, picosecond lasers could become more widely used by clinicians than longer-established laser modalities, with the added benefit of less downtime and higher efficacy.

To date, there is evidence of use of picosecond lasers in both pigment clearance $[2,3]$ and tissue remodeling with cases published showing efficacy in the appearance of nevus of Ota [4], minocycline-induced pigmentation [5], photo-aging [6] and acne scars [7].

Picosecond lasers used in all of the above conditions lead to improvement of dyspigmentation and/or textural change, with tolerable side effects of mild transient erythema and oedema [1].The sample sizes of the studies [4-8] were however small, ranging from 3 to 20 patients with an average follow-up of 3 months.

Practitioners should be aware of the range of uses of picosecond lasers beyond tattoo removal in order to ascertain their full potential; larger randomized control trials and split face studies could further inform future practice.

Faisal R. Ali

f.r.ali.01@ cantab.net

1 Dermatological Surgery and Laser Unit, St John's Institute of Dermatology, Guy's and St Thomas' NHS Foundation Trust, Guy's Hospital Cancer Centre, London SE1 9RT, UK
Compliance with ethical standards

Conflict of interest The authors declare that they have no conflicts of interest.

\section{References}

1. Forbat E, Al-Niaimi F (2016) The use of picosecond lasers beyond tattoos. J Cosmet Laser Ther 18:345-7

2. Reiter O, Atzmony L, Akerman L, Levi A, Kershenovich R, Lapidoth M, Mimouni D (2016) Picosecond lasers for tattoo removal: a systematic review. Lasers Med Sci 31:1397-405

3. Hsu VM, Aldahan AS, Mlacker S, Shah VV, Nouri K (2016) The picosecond laser for tattoo removal. Lasers Med Sci 31:1733-7

4. Chesnut C, Diehl J, Lask G (2015) Treatment of nevus of ota with a picosecond 755-nm alexandrite laser. Dermatol Surg 41:508-10

5. Rodrigues M, Bekhor P (2015) Treatment of minocycline-induced cutaneous pigmentation with the picosecond alexandrite $(755-\mathrm{nm})$ laser. Dermatol Surg 41:1179-82

6. Weiss RA, McDaniel DH, Weiss MA, Mahoney AM, Beasley KL et al (2016) Safety and efficacy of a novel diffractive lens array using a picosecond $755 \mathrm{~nm}$ alexandrite laser for treatment of wrinkles. Lasers Surg Med. doi:10.1002/1sm.22577

7. Brauer JA, Kazlouskaya V, AlabdulrazzaqH BYS, Bernstein LJ et al (2015) Use of a picosecond pulse duration laser with specialized optic for treatment of facial acne scarring. JAMA Dermatol 151:278-84

8. Wu DC, Fletcher L, Guiha I, Goldman MP (2015) Evaluation of the safety and efficacy of the picosecond alexandrite laser with specialized lens array for treatment of the photoaging décolletage. Lasers Surg Med 48:188-92 